\title{
EDITORIAL
}

\section{¿Hacia una Constitución ecológica?}

\author{
Valentina Durán Medina (iD) \\ Directora
}

Presentamos el número 15 de la Revista de Derecho Ambiental en un período histórico para Chile: el inicio de un proceso constituyente en medio de una pandemia.

En estas líneas ya nos hemos ocupado de la relación entre la pandemia y la crisis ambiental y climática (Durán Medina, Ossandón Rosales y Pulgar Martínez, 2020), y del período de «reflexión constitucional y climática» que se abrió con el estallido o revuelta social de octubre de 2019, que, entre otros efectos, impidió la realización de la $\mathrm{COP}_{25}$ en Chile. En función de esto afirmamos que:

Si la Constitución es un ejercicio para imaginar acuerdos para los próximos cincuenta años, no puede quedar fuera de esa hoja en blanco la responsabilidad de hacer frente a la crisis o catástrofe climática, que amenaza tan gravemente la vida del ser humano en el planeta (Durán Medina, Ossandón Rosales y Pulgar Martínez, 2019).

En 4 de julio de 2021 sesionará por primera vez la Convención Constitucional encargada de redactar y proponer una Nueva Constitución Política para Chile. De ahí, se abrirá un proceso que dará paso a la aceptación o al rechazo popular mediante un plebiscito constitucional con sufragio obligatorio para quienes tengan domicilio electoral en Chile. ${ }^{1}$

¿Cuán ecológica o ambientalista será la nueva Constitución chilena? Lo cierto es que, en las campañas electorales llevadas a cabo por los candidatos y las candidatas a convencionales constituyentes, se pudo apreciar un acentuado foco en la protección ambiental, en el que se propone el fin del extractivismo y la consideración del dere-

1. Según lo dispuesto por el Decreto 1684 exento del Ministerio del Interior y Seguridad Pública de 2021, que convoca a la primera sesión de instalación de la Convención Constitucional, según lo previsto en los artículos 2, 5, 130 y siguientes del Decreto Supremo 100 de 2005 del Ministerio Secretaría General de la Presidencia, que fija el texto refundido, coordinado y sistematizado de la Constitución Política de la República de Chile, según la Ley 21.20o, que modifica el Capítulo XV de la Constitución Política de la República, y según la Ley 21.221, que consiste en una reforma constitucional que establece un nuevo itinerario electoral para el plebiscito constituyente y otros eventos electorales. 
cho humano al agua. ${ }^{2}$ Los resultados de las elecciones confirman la tendencia y permiten observar un marcado interés, en los convencionales ya proclamados, en lograr una Constitución ecológica, a lo que se suma el triunfo de candidaturas de defensores y defensoras ambientales en distintos territorios. ${ }^{3}$

También en estas líneas, en diciembre de 2020, afirmamos y fundamentamos que la Universidad de Chile, a la cual pertenece esta revista del Centro de Derecho Ambiental, no es neutral con respecto a la democracia ambiental y al desarrollo sostenible, y que:

Por mandato tanto constitucional como legal, y no solo conforme a su visión, sino también a su misión institucional, tiene un papel relevante que cumplir en la acción climática y hacia un desarrollo sostenible y de protección de las generaciones futuras (Durán Medina, 2020).

Esto nos compromete, como centro académico, a entregar nuestros mejores esfuerzos para aportar a una discusión clave para el presente y el futuro de nuestro país.

Es por eso que, frente al debate constituyente que se ha iniciado en Chile, como equipo académico del Centro de Derecho Ambiental hemos querido plantear determinados contenidos mínimos que, estimamos, deben ser considerados en una nueva Constitución. En este contexto, hemos comprometido el quehacer académico de los próximos dos años con la reflexión de la integración del medio ambiente en el nuevo texto constitucional, en los términos en que los desafíos del siglo XXI exigen, definiendo una agenda estratégica que comprende la formación, la investigación y la extensión en esta materia. ${ }^{4}$

Para el equipo académico del Centro de Derecho Ambiental - integrado por los profesores Jorge Aranda Ortega, Ximena Insunza Corvalán, Sergio Montenegro Arriagada, Pilar Moraga Sariego, Ana Lya Uriarte, y quien suscribe, Valentina Durán Medina- los mínimos que, de manera ineludible, deben ser considerados en este proceso constituyente en relación con el medio ambiente son los siguientes: ${ }^{5}$

2. Verónica Droppelman y Benjamín Marchant, «Constituyentes: Candidatos con propuestas ambientales para la nueva Carta Magna», Ladera Sur, 15 de enero de 2021, disponible en bit.ly/3w5ubsM.

3. Así, «108 de los 155 representantes de la Convención declaran, como principio democrático clave, establecer el agua como un derecho humano y plantean la regulación o, directamente, el término de los derechos de aprovechamiento en manos de privados. Adicionalmente, más de un tercio de los constituyentes independientes son declarados defensores ambientales en sus respectivos territorios». Para más información, véase Héctor Cossio López, «Convención ambientalista: Más de un 70\% de constituyentes respalda cambiar modelo de gestión del agua», 18 de mayo de 2021, El Mostrador, disponible en bit.ly/363Q44hm.

4. La actividad desarrollada por el Centro de Derecho Ambiental y sus integrantes, desde 2016, en torno a los temas de medio ambiente y Constitución se consigna en la sección «Medio Ambiente y Constitución», disponible en http://uchile.cl/d173248.

5. En lo que sigue se reproduce parcialmente la declaración suscrita por las profesoras y los profesores 
1. La redefinición de los términos de la garantía constitucional. De acuerdo con la redacción de la Constitución de 1980, su artículo 19, número 8, «asegura a todas las personas el derecho a vivir en un medio ambiente libre de contaminación». En la actualidad, esta definición es interpretada en términos mucho más amplios que el tenor literal del texto, de una manera mucho más cercana al contenido del derecho a un ambiente sano. Cabe recordar que 85 países han consagrado este derecho bajo diversas expresiones como: «derecho a un ambiente de calidad», «derecho a un ambiente sano», "derecho a un ambiente limpio» y "derecho a un ambiente equilibrado», asociándolo, en algunos casos, a los deberes del Estado y de la sociedad, así como a los derechos de acceso a la información y participación en asuntos ambientales, los derechos de las generaciones futuras y otros derechos ambientales. Debe consagrarse un derecho a un ambiente equilibrado y saludable, que asegure la calidad de vida de las personas y la salud de los ecosistemas.

2. Efectividad de la protección ambiental y la acción climática. Si bien es cierto que más de 150 países en el mundo consagran la protección constitucional del medio ambiente, y que la legislación ambiental doméstica ha tenido un gran desarrollo en las últimas décadas, este último no ha ido acompañado de una mayor eficacia en la protección ambiental. Enfrentamos un gran desafío, dado el punto de no retorno en materia ambiental y climática en el que nos encontramos. Entonces, parece muy necesario comprender que el cuidado del ambiente, de la biodiversidad, de la naturaleza y de los ecosistemas, es indispensable para la sobrevivencia del ser humano en el planeta; y que la protección constitucional de estos fundamentos naturales de la vida, así como de los componentes socioculturales del medio ambiente, debe ser un eje transversal de una nueva Constitución, que se traduzca en principios, derechos y deberes. Igualmente importante es entregar al Estado herramientas efectivas para asegurar una gestión ambiental adecuada, lo que incluye profundizar las competencias de sus órganos y reforzar la coordinación de la Administración del Estado.

3. Redefinición de la función ecológica de la propiedad. La conflictividad ambiental del país se manifiesta, en gran medida, en la permanente tensión entre el derecho a vivir en un medio ambiente libre de contaminación y los derechos del orden público económico, que consagra la actual Constitución, en particular, el derecho de propiedad. Esta situación nos lleva a considerar la importancia de consagrar las características y el contenido de la función ecológica y social de la propiedad, en un contexto de fuerte presión sobre los recursos naturales.

4. Inclusión de principios ambientales. El actual texto constitucional carece de principios ambientales, a diferencia de lo que sucede en otros países de la región y del mundo, que han decidido incorporarlos, atendido el papel que ellos juegan como inspiración del quehacer social y, particularmente, en la formulación de políticas públicas. Por ello, estimamos indispensable la consagración constitucional de, a lo

mencionados, titulada «Nueva Constitución del siglo XXI: Un desafío para el derecho ambiental», y que está disponible http://uchile.cl/d173249. 
menos, los siguientes principios: preventivo, precautorio, de desarrollo sostenible, equidad intergeneracional, justicia ambiental, progresividad y no regresión.

5. La inclusión de más derechos. El desarrollo constitucional de la protección del medio ambiente ha significado la consagración de otros derechos ambientales, entre los cuales destacan los derechos de acceso a la información, a la participación y a la justicia en asuntos ambientales. En esta materia, el Acuerdo de Escazú entrega ciertas directrices y estándares que deben estar presentes en el debate constitucional.

6. El teriritorio, la gestión y el medio ambiente. La gestión regional y local es un aspecto fundamental de la eficacia de la protección ambiental. Por ello, las menciones a la descentralización efectiva son clave. En esta materia, la definición de la organización territorial y administrativa, de los mecanismos de participación en materia ambiental en el nivel local, y el reconocimiento y el respeto de las vocaciones territoriales, debieran ser temas a tratar en el proceso constituyente que se inicia, así como la promoción de espacios deliberativos y de debida rendición de cuentas, y la necesaria mención al enfoque de género que debe acompañar a la gestión ambiental.

Como expresión del compromiso descrito, en el día del solsticio de invierno, 21 de junio de 2021, nuevo día feriado de los pueblos indígenas (We Tripantu en la cultura mapuche) que marca y acoge el crecimiento de nueva vida, inauguramos un preciado proyecto: el Observatorio Constitucional Ambiental. Esto se llevó a cabo a través de un acto que contó con la participación del rector de la Universidad de Chile, doctor Ennio Vivaldi, el decano de la Facultad de Derecho, profesor Pablo Ruiz-Tagle, y de los constituyentes Patricio Fernández, Elisa Giustinianovich, Hernán Larraín y Bárbara Sepúlveda, quienes participaron de un conversatorio moderado por la profesora Ana Lya Uriarte luego de la presentación del proyecto por parte de todo su equipo de trabajo. ${ }^{6}$

El objetivo general del Observatorio Constitucional Ambiental es constituir un aporte académico a la transparencia, la visibilización y al conocimiento ciudadano con respecto a las temáticas, posiciones y deliberaciones que, en torno al tema ambiental, se desarrollen en el seno de la Convención Constitucional, incidiendo, desde una mirada académica, en el proceso y su resultado. Como objetivos específicos, el Observatorio busca:

- Hacer seguimiento del desarrollo del debate con respecto a cada una de las temáticas ambientales surgidas en las sesiones de la Convención Constitucional.

- Informar a la comunidad universitaria y a la sociedad civil mediante comu-

6. Para mayor información, véase Nicolás Yáñez, Francisca Standen y Vicente Díaz, «CDA lanza Observatorio Constitucional Ambiental», Universidad de Chile. Facultad de Derecho, 22 de junio de 2021, disponible en http://uchile.cl/d177210. 
nicaciones en distintos formatos, a través de redes sociales y plataformas, el estado de avance de las discusiones constitucionales ambientales relevantes.

- Poner a disposición de la Convención y de la ciudadanía la experiencia y el conocimiento del equipo académico de la Facultad de Derecho, ofreciendo material académico de consulta para los constituyentes en temáticas ambientales relevantes.

- Articular, en colaboración con las unidades académicas de la Facultad de Derecho, y con los programas y centros académicos de la Universidad de Chile vinculados al área, contribuciones interdisciplinarias a la discusión constitucional.

- Incidir sustantivamente en la discusión constitucional a partir de los lineamientos fijados por el cuerpo académico del Centro de Derecho Ambiental en su documento de «Mínimos constitucionales Centro de Derecho Ambiental: Nueva Constitución del siglo XXI: Un desafío para el derecho ambiental».

- Al término del trabajo de la Convención, evaluar críticamente los aspectos ambientales de la carta fundamental propuesta y eventualmente aprobada por la ciudadanía, mediante productos de investigación relevantes.

Esperamos que este número, compuesto por cinco artículos de investigación, todos muy diversos y que abordan temas de interés nacional e internacional para el desarrollo del derecho ambiental, sea de agrado para nuestros lectores y sirvan para avanzar, desde la perspectiva académica, en los mínimos comunes de una nueva Constitución para Chile.

Finalmente, sin duda son tiempos difíciles, por lo que agradezco muy especialmente el esfuerzo de las autoras y de los autores de este número, de los pares revisores que estuvieron disponibles y, como siempre, el esfuerzo y compromiso de los coeditores Jorge Ossandón y Antonio Pulgar, así como de todo el equipo editorial.

\section{Referencias}

Durán Medina, Valentina, Jorge Ossandón Rosales y Antonio Pulgar MarTíneZ (2020). «Reflexiones sobre el derecho ambiental en tiempos de pandemia». Revista de Derecho Ambiental, 13: 1-5. DOI: 10.5354/0719-4633.2020.57825.

-.(2019). «Necesario período de reflexión constitucional y climática entrela COP25 yla COP26». Revista de Derecho Ambiental, 12: 1-5. DOI: 10.5354/0719-4633.2019.55854.

Durán Medina, Valentina (2020). «La Universidad de Chile no es neutral con respecto a la democracia ambiental y el desarrollo sostenible». Revista de Derecho Ambiental, 14: 1-7. DOI: 10.5354/0719-4633.2020.60654. 


\section{Sobre la autora}

Valentina Durán Medina es abogada por la Universidad de Chile, máster en Derecho Ambiental por las universidades de París I Panthéon-Sorbonne y París II Panthéon-Assas. Además, es profesora asociada de la Facultad de Derecho de la Universidad de Chile, donde dirige el Centro de Derecho Ambiental. También es docente de los Departamentos de Enseñanza Clínica del Derecho y de Derecho Económico. Pertenece al claustro del magíster de la misma facultad, dirige la Revista de Derecho Ambientaly el diplomado de Derecho Ambiental e Instrumentos de Gestión. Su correo electrónico es vduran@derecho.uchile.cl. (D) http://orcid.org/oooo-0002-9347-1017. 
La Revista de Derecho Ambiental, del Centro de Derecho Ambiental de la Facultad de Derecho de la Universidad de Chile, es un espacio de exposición y análisis en el plano académico del derecho ambiental. Su contenido se presenta a través de doctrina, jurisprudencia y recensiones, y aborda diversas materias relacionadas con la gestión, institucionalidad y herramientas de protección ambiental y desarrollo sustentable. Se presentan artículos de diferentes autores y autoras en los que se analizan y abordan casos y temas jurídico-ambientales de creciente interés y actualidad.

\author{
DIRECTORA \\ Valentina Durán Medina \\ EDITORES \\ Jorge Ossandón Rosales \\ y Antonio Pulgar Martínez \\ SITIO WEB \\ revistaderechoambiental.uchile.cl \\ CORREO ELECTRÓNICO \\ revistada@derecho.uchile.cl \\ LICENCIA DE ESTE ARTÍ́CULO \\ Creative Commons Atribución Compartir Igual 4.o Internacional
}

La edición de textos, el diseño editorial

y la conversión a formatos electrónicos de este artículo

estuvieron a cargo de Tipográfica

(www.tipografica.io) 